IKONOMIKA: Journal of Islamic Economics and Business

Volume 2, No I (20I7)

ISSN: 2527-3434 (PRINT) - ISSN: 2527-5I43 (ONLINE)

Page : $53-62$

\title{
Determinan Volume Pembiayaan Bank Umum Syariah Indonesia
}

\author{
Masudah \\ Universitas Muhammadiyah Prof. DR. Hamka \\ masudah258@gmail.com
}

\begin{abstract}
As a financial intermediary institution, Islamic banking should give a financing to deficit units. The aim of this study is to emphasize the factors that had an influence to financing in Islamic banks. This research using panel data regression with II Islamic full-pledge banks from 2011 until 2015. The result shows that deposit funds, exchange rate, operational efficiency ratio and interest rate had an impact on Islamic bank's financing, but other variables such as non-performing financing and inflation doesn't had an impact. From F-test shows that all variables simultaneously had an impact on Islamic bank's financing. Besides that, the value of adjusted $R$ square shows that all of the independent variables can explain the model about $78.5 \%$, the others explained by other variables outside the model.
\end{abstract}

Keywords: Islamic Banks, Financing, Panel Regression

\begin{abstract}
Abstrak
Perbankan syariah sebagai lembaga intermediasi berkewajiban untuk memberikan pembiayaan kepada pihak yang membutuhkan dana. Penelitian ini bertujuan untuk menjelaskan faktor-faktor yang berpengaruh terhadap volume pembiayaan di bank umum syariah. Penelitian ini menggunakan regresi data panel dengan II bank umum syariah dari tahun 2011 sampai dengan 2015. Hasil menunjukkan bahwa dana pihak ketiga, nilai tukar, rasio efisiensi operasional (BOPO), dan tingkat suku bunga berpengaruh terhada volume pembiayaan di bank syariah. Akan tetapi, variabel lainnya seperti tingkat pembiayaan bermasalah (NPF) dan inflasi tidak berdampak terhadap volume pembiayaan bank umum syariah. Nilai uji $F$ menunjukkan bahwa seluruh variabel bebas secara simultan berdampak kepada volume pembiayaan di bank syariah. Selain itu, nilai koefisien determinasi menunjukkan bahwa seluruh variabel bebas mampu menjelaskan model sebesar 78.5\%, dan sisanya dijelaskan oleh variabel lain di luar model.
\end{abstract}

Kata Kunci: Bank Syariah, Pembiayaan, Regresi Panel. 


\section{A. PENDAHULUAN}

Dampak undang-undang perbankan Islam memberikan hal yang positif bagi perkembangan perbankan syariah di Indonesia, hal ini dibuktikan dengan semakin banyaknya bank-bank yang melakukan kegiatan usaha berdasarkan prinsip syariah. Data perkembangan lembaga perbankan syariah dari tahun 2010 sampai dengan tahun 2015 mengalami peningkatan yang pesat. Sebagaimana bank konvensional, Bank syariah juga menjalankan fungsi intermediasi, dimana sebagian besar aktifitasnya yaitu mengumpulkan dana dan menyalurkan dana dalam bentuk kredit atau pembiayaan pada perbankan syariah. Pembiayaan merupakan hal yang paling dominan untuk diperhatikan dalam segenap aktivitas perbankan karena selain untuk memperluas pangsa pasarnya pembiayaan juga menjadi sumber utama pendapatan bank syariah.

Berdasarkan data Statistik Perbankan Syariah Indonesia, dari tahun 201 I sampai dengan tahun 2015 jumlah penyaluran dana (pembiayaan) yang dilakukan bank syariah di Indonesia terus mengalami peningkatan. Tahun 20II total pembiayaaan yang diberikan sebesar Rp 291,232,505 atau tumbuh 23.84\% dari tahun sebelumnya, tahun 2012 total pembiayaan yang diberikan $\mathrm{Rp} 393,120,445$ tumbuh sebesar $34.98 \%$ dari tahun sebelumnya dan di tahun 2013 total pembiayaan yang diberikan naik sebesar $\mathrm{Rp}$ 517,419,083 namun persentase pertumbuhan menurun dibandingkan tahun sebelumnya yaitu sebesar $31.62 \%$, tahun 2014 persentase pertumbuhan pembiayaan menurun dari tahun sebelumnya yaitu 9.62\% dengan jumlah pembiayaan yang disalurkan sebesar Rp 567,2I0,175 dan di tahun 2015 meskipun persentase total pembiayaan yang disalurkan terus menurun dari tahun sebelumnya yaitu sebesar $7.15 \%$ namun secara periode tahun jumlah pembiayaan selalu meningkat yaitu sebesar Rp 607,782,333.

Faisol (2017) menyatakan bahwa pembiayaan bank syariah akan mampu memberikan pengaruh terhadap kinerja dari usaha kecil dan menengah.Ada beberapa faktor yang mempengaruhi volume pembiayaan baik itu faktor dari dalam bank (internal) seperti non-performing financing (NPF), biaya operasional dan pendapatan operasional (BOPO) dan dana pihak ketiga (DPK), maupun dari luar bank (eksternal). Faktor ekternal yang mempengaruhi volume pembiayaan dapat berasal dari kondisimakroekonomi seperti inflasi, suku bunga, dan nilai tukar. Kebijakan pemisahan (spin-off) yang telah mulai dilakukan pada tahun 2008, telah mampu meningkatkan jumlah penyaluran pembiayaan. Meskipun Al Arif (20I5) menemukan bahwa tidak terdapat perbedaan penyaluran pembiayaan antara sebelum dan sesudah kebijakan pemisahan. 
Tabel I menunjukkan besaran BOPO, NPF, inflasi, nilai tukar, BI rate, dan pembiayaan Bank Umum Syariah (BUS) Syariah tahun 20I I-20I5.

\section{Tabel I}

Data Pertumbuhan NPF, BOPO, Inflasi, BI Rate, Nilai Tukar Tahun 20II-20I5

\begin{tabular}{|c|c|c|c|c|c|}
\hline Tahun & 2011 & 2012 & 2013 & 2014 & 2015 \\
\hline NPF & $2,52 \%$ & $2,22 \%$ & $2,62 \%$ & $4,95 \%$ & $4,84 \%$ \\
\hline $\mathrm{BOPO}$ & 78,4I\% & $74,97 \%$ & $78,21 \%$ & $96,97 \%$ & $97,01 \%$ \\
\hline DPK & II 5,4 I5 & $\mathrm{I} 47,5 \mathrm{I} 2$ & I83.534 & 217.858 & 23I.I75 \\
\hline Inflasi & $3.79 \%$ & $4.30 \%$ & $8.38 \%$ & $8.36 \%$ & $8.36 \%$ \\
\hline Nilai Tukar & $9,068,00$ & $9,670,00$ & $\begin{array}{c}\text { I2,I89.0 } \\
0\end{array}$ & $\mathrm{I} 2,440.00$ & $13,795.00$ \\
\hline BI rate & $6.00 \%$ & $5.75 \%$ & $7.50 \%$ & $7.75 \%$ & $7.50 \%$ \\
\hline Pembiayaan & $291,232,5$ & 393,I20, & $5 \mathrm{I} 7,4 \mathrm{I} 9$ & $567,2 \mathrm{IO}, \mathrm{I}$ & $607,782,3$ \\
\hline IIBUS & 05 & 445 & 083 & 75 & 33 \\
\hline Pertumbuhan & $23,84 \%$ & $34,98 \%$ & $31,62 \%$ & $9,62 \%$ & $7,15 \%$ \\
\hline
\end{tabular}

Sumber data: laporan publikasi BI (diolah)

Berdasarkan Tabel I dapat dilihat jelas adanya ketidaksesuaian teori terkait BOPO dan NPF dimana kenaikan variabel tersebut akan menurunkan jumlah pembiayaan. Kenaikan BOPO dan NPF pada tahun 2012-2013 tidak membuat jumlah pembiayaan yang disalurkan oleh bank umum syariah menurunkan.Begitu pula dengan inflasi, nilai tukar, suku bunga.Jika dilihat pada hukum atau teori inflasi dan nilai tukar dimana kenaikan variabel ini akan menurunkan permintaan pembiayaan sehingga volume pembiayaanpun juga akan mengalami penurunan, tetapi dalam kenyataannya kenaikan inflasi sebesar $4,30 \%$ dan nilai tukar sebesar Rp 9,670,00pada tahun 20I2tidak diikuti dengan penurunan jumlah pembiayaan, sebaliknya persentase jumlah pembiayaan meningkat dibandingkan dengan tahun sebelumnya dari $23,84 \%$ menjadi $34,98 \%$. Sedangkan teori suku bunga, kenaikan suku bunga menyebabkan kenaikan permintaan pembiayaan alternatif bank syariah faktanyapun tidak demikian, kenaikan suku bunga sebesar 7,50\% pada tahun 2013 dan $7,75 \%$ pada tahun 20I4tetapi persentase jumlah pembiayaan malah turundari tahun sebelumnya, yaitu dari $34,98 \%$ di tahun 2012 turun menjadi $31,62 \%$ ditahun 2013 dan 9,62\% ditahun 2014.

Berdasarkan uraian diatasdapat diketahui bahwa terdapat phenomena gapdan research gap.Phenomena gap yang terjadi dapat dilihat pada Tabel I dimana terdapat ketidakkonsistenan antara data dengan teori yang ada. 


\section{B. METODE}

Sumber data yang digunakan dalam penelitian ini berasal dari laporan jumlah pembiayaan II Bank Umum Syariah di Indonesia, data triwulan NPF, BOPO, DPK, inflasi, nilai tukar dan suku bunga. Data didapatkan dari statistik perbankan syariah yang dipublikasikan pada lamanBank Indonesia, Otoritas Jasa Keuangan (OJK)sepanjang tahun 2015. Teknik analisis data dalam penelitian ini adalah menggunakan analisis regresi data panel. Model regresi panel yang dipergunakan dalam penelitian ini ialah:

Pembiayaan $_{\text {it }}=\alpha+\beta_{\mathrm{INPF}} \mathrm{it}+\beta_{2} \mathrm{BOPO}_{\mathrm{it}}+\beta_{3} \mathrm{DPK}_{\mathrm{it}}+\beta_{4 \text { inflasit }}+\beta_{s k u r s t}+\beta_{6} \mathrm{BI}$ rate $_{\mathrm{t}}+\varepsilon_{\mathrm{it}}$

Setelah menguji metode yang paling tepat antara common, fix dan random effect dengan uji Chow dan uji Haussman. Selanjutnya akan dilakukan pengujian hipotesis dengan: pertama, uji t dilakukan untuk menguji apakah setiap variabel bebas (independen) secara masing-masing parsial memiliki pengaruh yang signifikan terhadap variabel terikat (dependen). Kedua, uji $\mathrm{F}$ digunakan untuk menguji pengaruh variabel independen secara simultan terhadap variabel dependen. Ketiga, uji koefisien determinasi $\left(\mathrm{R}^{2}\right)$ ditujukan untuk menilai seberapa besar kemampuan variabel independen menjelaskan variabel dependen.

\section{HASIL DAN PEMBAHASAN}

\section{Hasil}

Langkap pertama untuk mengetahui model panel yang akan digunakan ialah dengan melakukan uji Chow. Uji ini dipergunakan untuk mengetahui apakah penelitian ini menggunakan model pooled least square ataukah model efek tetap (fixed effect model). Hasil empiris memperlihatkan nilai F-Statistik adalah I7.86846I dan nilai probabilitas F-Statistik sebesar 0.0000 yang berarti bahwa nilai probabilitas F-Statistik lebih kecil dari tingkat signifikansi $\alpha$ 5\% $(0.0000<$ 0.05). Maka $\mathrm{H}_{0}$ ditolak, sehingga model panel yang digunakan adalah Fixed Effect (FEM).

Selanjutkan kita akan melakukan uji Haussman, dimana uji ini dipergunakan untuk menentukan apakah akan menggunakan model efek tetap (fixed effect model) ataukah model efek acak (random effect model). Hasil empiris menunjukkan bahwa nilai probababilitas F- Statistik lebih besar dari taraf nyata yakni sebesar 1.0000, yang artinya menolak hipotesis untuk menggunakan fixed effect dan menerima hipotesis untuk menggunakan random effect, sehingga model panel yang digunakan adalah Random Effect Model(REM). 
Model data panel yang digunakan dalam penelitian ini adalah dengan menggunakan model Random Effect (REM) dapat dijelaskan melalui persamaan sebagai berikut:

Pembiayaan $=-8.641365+0.00027 \mathrm{INPF}-0.002987 \mathrm{BOPO}+$ $0.7078 \mathrm{I} 6 \mathrm{DPK}$

$$
\text { + 0.010596INF + I.5I7657KURS - 0.I I6599BI_RATE }
$$

Tabel 2 menunjukkan hasil pengujian hipotesis pada penelitian ini. Hal pertama yang dilakukan dalam pengujian hipotesis ialah uji t. Uji ini dipergunakan untuk menguji apakah secara individu variabel bebas memengaruhi variabel terikat.

\section{Tabel 2}

\section{Hasil Uji Statistik}

Dependendt variable: Pembiayaan

Periods included: 20

Cross-section included: II

Total panel observation: 220

\begin{tabular}{|c|c|c|c|c|}
\hline Variable & Coeff & S.E. & t-Stat & Prob \\
\hline C & $-8.64 I 365$ & $\mathrm{I} .65675 \mathrm{I}$ & $-5.2 \mathrm{I} 585 \mathrm{I}$ & 0.0000 \\
\hline $\mathrm{NPF}$ & $0.00027 \mathrm{I}$ & 0.003042 & $0.08906 \mathrm{I}$ & $0.929 \mathrm{I}$ \\
\hline $\mathrm{BOPO}$ & -0.002987 & 0.001381 & -2.161905 & $0.03 I 7$ \\
\hline DPK & 0.707816 & 0.030764 & 23.00777 & 0.0000 \\
\hline Inflasi & 0.010596 & 0.016337 & 0.648628 & $0.5 \mathrm{I} 73$ \\
\hline Kurs & I.5I7657 & $0.2179 \mathrm{I} 2$ & 6.964543 & 0.0000 \\
\hline BI_rate & -0.116599 & 0.048675 & -2.395445 & 0.0175 \\
\hline \multicolumn{5}{|c|}{ Effect specification } \\
\hline Cross-section random & & & 0.193532 & 0.2925 \\
\hline Idiosyncrate random & & & 0.301005 & 0.7075 \\
\hline R-squared & 0.793373 & & F-stat & I36.3072 \\
\hline Adj R-squared & 0.787553 & & Prob & 0.00000 \\
\hline
\end{tabular}

Tabel 2 merupakan hasil pengujian variabel independen yaitu NPF, BOPO, DPK, Inflasi, Kurs dan BI Rate terhadap volume pembiayaan secara parsial.Dari Tabel I.4 diatas menunjukkan bahwa koefisien model regresi memiliki nilai koefisien sebesar -8.64I365 dengan nilai t-statistic sebesar -5.2I585I dan nilai probabilitas sebesar 0.0000.Konstanta sebesar -8.64I365 menandakan bahwa jika variabel independen konstan maka rata-rata pembiayaan adalah sebesar 8.64I365.Hasil dari Tabel 2 menunjukkan bahwa NPF tidak berpengaruh 
terhadap pembiayaan. Selain itu, hasil empiris turut pula menunjukkan bahwaBOPO berpengaruh negatif terhadap pembiayaan.

Hasil dari Tabel 2 menunjukkan bahwa DPK berpengaruh positif terhadap pembiayaan. DPK memiliki nilai koefisien sebesar 0.7078I6. Hal ini menunjukkan jika DPK mengalami peningkatan I satuan, maka akan meningkatkan pembiayaan sebesar 0.707816 satuan, dengan catatan variabel lain dianggap konstan. Inflasi tidak berpengaruh terhadap pembiayaan. Variabel kurs berpengaruh positif dan signifikan terhadap pembiayaan. Kurs memiliki nilai koefisien sebesar I.5I7657. Hal ini menunjukkan jika kurs mengalami peningkatan I satuan, maka akan meningkatkan pembiayaan sebesar I.5I7657 satuan, dengan catatan variabel lain dianggap konstan. Variabel BI Rate berpengaruh negatif terhadap pembiayaan. BI Rate memiliki nilai koefisien sebesar -0.I I6599. Hal ini menunjukkan jika BI Rate mengalami peningkatan I satuan, maka akan menurunkan pembiayaan sebesar 0.I 16599satuan, dengan catatan variabel lain dianggap konstan.

Berdasarkan Tabel 2, hasil regresi data panel menggunakan Random Effect Model (REM) diperoleh nilai F-statistik sebesar I36.3072dengan nilai probabilitas sebesar 0.000000 . Hal ini menunjukkan bahwa Non Performing Financing (NPF), Biaya Operasional Pendapatan Operasional (BOPO), Dana Pihak Ketiga (DPK), Inflasi, Kurs, dan BI Rate berpengaruh signifikan terhadap jumlah pembiayaan.

Nilai koefisien determinasi (adjusted $R^{2}$ ) sebesar 0.787553 atau 78.75\%.Dapatdisimpulkanbahwa seluruh variabel bebas berpengaruh terhadap volume pembiayaanBank Umum Syariah adalah $78.75 \%$. Sedangkansisanya sebesar $21.25 \%$ dipengaruhi oleh variabel-variabel lain yang tidak dimasukkan kedalam penelitian ini.

\section{Pembahasan}

Hasil empiris menunjukkanbahwa variabel NPFtidak berpengaruhterhadapvolume pembiayaan Bank Umum Syariah. Hasil penelitian ini berbeda dengan Katmas (20I4), Furqaini dan Yaya (2016)Adzimatinur, dkk (2016) dan Husaeni (2017) menunjukkan bahwa NPF berpengaruh terhadap volume pembiayaan. Hasilpenelitianserupa dengan Hendri, dkk(20I2) yang NPF tidakberpengaruh terhadap volume pembiayaan Bank Syariah. Hal ini menunjukkan bahwa kegiatan pembiayaanyang dilakukan bank akan tetap berjalan walaupun NPFyang dimiliki perusahaan mengalami peningkatan atau pun penurunan, selama nilai pembiayaan bermasalah (NPF) masih dalam batas aman.

Nilai BOPO berpengaruh negatif terhadap volume pembiayaan Bank Umum Syariah.Hal ini disebabkan karena tingkat efisiensi bank dalam menjalankan 
operasinya berpengaruh terhadap pendapatan yang dihasilkan oleh bank tersebut.Hasil penelitian serupa dengan hasil penelitianyang dilakukanolehKatmas (20I4) menyimpulkanbahwa BOPOberpengaruh negatif signifikan terhadap volume pembiayaanBank Syariah.BOPO memberikan indikasi bahwa apabila manajemen mampu menekan $\mathrm{BOPO}$ yang berarti efisiensi meningkat akan sangat signifikan terhadap kenaikan jumlah pembiayaan yang disalurkan. Berbeda dengan hasil penelitian Nugraha (20I4), Adzimatinur, dkk (20I6), dan Wahyudi (20I6), dimana BOPO tidak berpengaruh terhadap pembiayaan.

Hasil empiris menunjukkanbahwa variabelDPK berpengaruh positif dan signifikan terhadapvolume pembiayaan Bank Umum Syariah.Hasil penelitianserupa dengan hasilpenelitianyang dilakukanolehNasihin (2013), Adzimatinur, dkk (20I6) Furqaini dan Yaya (20I6), Wahyudi (2016), dan Husaeni (20I7),dimana DPKberpengaruh positifterhadap pembiayaan Bank Syariah.Sehingga dapat diartikan bahwa semakin meningkat aliran dana pihak ketiga yang masuk kedalam kas bank syariah akan semakin meningkatkan kegiatan pembiayaan bank. Kondisi ini terjadi karena bertambahnya aliran dana pihak ketiga yang dilihat dari jumlah tabungan, jumlah giro dan deposito tentu akan membuat aliran dana yang dapat dimanfaatkan bank untuk melaksanakan kegiatan pembiayaan akan semakin meningkat.

Selain itu, variabelinflasi tidak berpengaruh terhadapvolume pembiayaan Bank Umum Syariah.Hasil penelitian serupa dengan hasilpenelitianyang dilakukanolehDarma dan Rita (20II), Firaldi (2013), dan Dahlan dan Ardiyanto (2015)menyimpulkanbahwa inflasi tidak berpengaruh terhadapvolume pembiayaan Bank Syariah.Meningkatnya laju inflasi tidak mengurangi kegiatan bank syariah dalam menyalurkan dana yang dihimpunnya. Hal ini disebabkan kondisi inflasi pada periode penelitian relatif stabil dan inflasi yang terjadi adalah inflasi ringan (di bawah I0\% per tahun) sehingga tidak berpengaruh terhadap volume pembiayaan dan bank umum syariah dapat menjalankan fungsi intermediasi dengan baik.

Kemudian, variabel nilai tukar (kurs) berpengaruh positif terhadapvolume pembiayaan Bank Umum Syariah.Hasil penelitian serupa dengan hasilpenelitianyang dilakukanolehEzhar (20I4) menyimpulkan bahwa kurs berpengaruh positif terhadap volume pembiayaan.Dapat disimpulkan bahwa terdepresiasinya mata uang rupiah tidak mengurangi kegiatan bank syariah dalam menyalurkan pembiayaan kepada masyarakat.Hal ini disebabkan kondisi terdepresiasinya mata uang rupiah pada periode penelitian relatif stabil dan tidak terjadi dalam kurun waktu yang lama.Selain itu transaksi bank umum syariah masih didominasi oleh transaksi lokal dan jarang bersentuhan dengan mata uang 
asing.Sehingga kurs berpengaruh positif terhadap volume pembiayaan. Penelitian Darma \& Rita (20II) menunjukkan nilai tukar berpengaruh negatif terhadap pembiayaan.Hasil penelitian berbeda terdapat pada Ezhar(20I4) dimana nilai tukar mempunyai pengaruh yang positif terhadap penyaluran kredit.

Variabel BI Rateberpengaruh negatif terhadap volume pembiayaan Bank Umum Syariah. ketika BI rate naik, maka bank bank umum syariah akan membebankan nilai pricing (margin dan bagi hasil) yang lebih tinggi bagi pembiayaannya. Nasabah yang membutuhkan dana akan cenderung menunda atau membatalkan rencana pembiayaannya sehingga sehingga volume pebiayaannya akan turun. Sedangkan ketika BI rate turun, maka bank umum syariah akan membebankan nilai pricing (margin dan bagi hasil) yang lebih rendah bagi pembiayaannya. Nasabah yang membutuhkan dana akan cenderung untuk melaksanakan rencana pembiayaannya sehingga sehingga volume pebiayaannya akan naik.Penelitian ini bertolak belakang dengan penelitian Katmas (20I4) dimana suku bunga berpengaruh positif terhadap jumlah pembiayaan.

Salah satu hal yang menjadi kelemahan dari bank syariah di Indonesia saat ini ialah tingginya marjin pembiayaan yang ditawarkan. Hal ini diakibatkan oleh tingginya biaya dana (cost of funds) dari bank syariah, karena dana pihak ketiga didominasi (sekitar 60\%) oleh deposito. Oleh karenanya bank syariah harus melakukan beberapa langkah strategis guna pengembangan industrinya. Rusydiana (2016) menyebutkan bahwa terdapat beberapa langkah yang dapat dilakukan oleh perbankan syariah: (I) Memperkuat permodal dan skala usahanya; (2) Meningkatkan kualitas dan kuantitas sumber daya manusia; (3) Memperkuat struktur pendanaan bank syariah.

\section{SIMPULAN}

Berdasarkan uji regresi data panel pada uji hipotesis (Uji-t) ditemukan bahwa secara parsial variabel BOPO, DPK, nilai tukar (kurs) dan BI rate berpengaruh terhadap jumlah penyaluran pembiayaan bank syariah. Sedangkan variabel NPF dan inflasi tidak berpengaruh terhadap jumlah penyaluran pembiayaan bank syariah. Nilai uji F menunjukkan bahwa secara simultan seluruh variabel bebas berpengaruh terhadap jumlah penyaluran pembiayaan bank syariah.

Bagi bank syariah, diharapkan agar pihak manajemen bank umum syariah mampu mengurangi rasio NPF dalam pembiayaan bermasalah yang terjadi, mengefisiensikan rasio BOPO dalam menekan biaya operasional dan meningkatkan pendapatan operasional, dan meningkatkan jumlah DPK agar dapat menyalurkan pembiayaan secara efektif, sehingga profitabilitas yang dihasilkan akan maksimal 
serta dapat menjadikan fluktuasi kurs dan BI rate sebagai peluang dengan pengelolaan managemen yang baik selama kondisi tersebut.

Bagi pengguna laporan keuangan dalam mengambil keputusan untuk berinvestasi, investor dapat melihat $\mathrm{BOPO}$, DPK, kurs dan BI rate yang memberikan adanya pengaruh terhadap peningkatan volume pembiayaan untuk melihat gambaran bagaimana kondisi perusahaan dapat menguntungkan atau tidak sebagai media investasi. Karena semakin bagus dan besar jumlah pembiayaan yang disalurkan, investor akan semakin tertarik untuk berinvestasi.

Untuk penelitian selanjutnya, penelitian dapat ditambah dengan variabel lain yang mempengaruhi volume pembiayaan pada bank syariah. Penelitian ini juga dapat dikembangkan dengan memperluas model penelitian sebelumnya. Menggunakan metode dan alat uji yang lebih lengkap dan akurat sehingga diperoleh kesimpulan yang lebih valid. Memperluas penelitian dengan cara memperpanjang periode penelitian dengan menambahkan tahun penelitian, juga memperbanyak sampel untuk penelitian yang akan datang.

\section{PUSTAKA ACUAN}

Adzimatinur, F., Hartoyo, S. dan Wiliasih. R. (2016). Faktor-faktor yang Mempengaruhi Besaran Pembiayaan Perbankan Syariah di Indonesia. AlMuzara'ah. Vol. 4 (2): I06-I22.

Al Arif, M.N.R. (20I5). The Effect of Spin-off Policy on Financing Growth in Indonesian Islamic Banking Industry. Al-Ulum. Vol. I5 (I): I73-I84.

Amelia, E. dan Hardini, E.F. (2017). Determinant of Mudharabah Financing: A Study at Indonesian Islamic Rural Banking. Etikonomi, Vol. I6 (I): 43-52.

Dahlan, R. dan Ardiyanto, I. (20I5). Pengaruh Tingkat Bonus SBIS dan Tingkat Inflasi Terhadap Penyaluran Pembiayaan Bank Syariah di Indonesia. Equilibrium. Vol. 3 (I): 62-85.

Darma, E.S. dan Rita. (20I I). Faktor-Faktor Yang Berpengaruh Terhadap Tingkat Pengguliran Dana Bank Syariah. Jurnal Akuntansi dan Investasi. Vol. I2 (I): $72-87$.

Ezhar, M.T. (20I4). Analisis Pengaruh Kondisi Makro Ekonomi Terhadap DPK dan Kinerja Keuangan Serta Dampaknya Terhadap Penyaluran Kredit Pada Bank Persero Periode 2008-2012. (Skripsi Tidak Dipublikasikan). Jakarta: UIN Syarif Hidayatullah Jakarta.

Faisol. (2017). Islamic Bank Financing and It's Impact on Small Medium Enterprise's Performance. Etikonomi. Vol. I6 (I): I3-24. 
Firaldi, M. (2013). Analisis Pengaruh DPK, NPF, dan Inflasi Terhadap Total Pembiayaan yang Diberikan oleh BPRS di Indonesia Periode 2007-20I2. (Skripsi Tidak Dipublikasikan). Jakarta: UIN Syarif Hidayatullah Jakarta.

Furqaini, N. dan Yaya, R. (2016). Faktor-faktor yang Mempengaruhi Volume dan Porsi Pembiayaan Berbasis Bagi Hasil Pada Perbankan Syariah di Indonesia. JRAK, Vol. 7 (I): 22-38.

Hendri, Ethika, dan Darmayanti. (2012). Faktor-faktor Yang Mempengaruhi Volume Pembiayaan Berbasis Bagi Hasil Pada Perbankan Syariah di Indonesia. OJS Universitas Bung Hatta. Vol. 2 (I): I7I-I80.

Husaeni, U.A. (2017). Determinan Pembiayaan Pada Bank Pembiayaan Rakyat Syariah di Indonesia. Esensi: Jumnal Bisnis dan Manajemen. Vol. 7 (I): 4962.

Katmas, E. (20I4). Pengaruh Faktor Eksternal dan Internal Terhadap Volume Pembiayaan Perbankan Syariah di Indonesia. (Skripsi Tidak Dipublikasikan). Jakarta: UIN Syarif Hidayatullah Jakarta.

Nasihin. (2013). Pengaruh Faktor Internal Bank Terhadap Volume Pembiayaan Bank Syariah di Indonesia. (Skripsi Tidak Dipublikasikan). Yogyakarta: UIN Sunan Kalijaga Yogyakarta.

Nugraha, S. (20I4). Pengaruh ROA, NPF, FDR, BOPO, dan Tingkat Bagi Hasil Terhadap Pembiayaan Mudharabah. (Skripsi Tidak Dipublikasikan). Jakarta: UIN Syarif Hidayatullah Jakarta.

Rusydiana, A.S. (2016). Analisis Masalah Pengembangan Perbankan Syariah di Indonesia: Aplikasi Metode Analytic Network Process. Esensi: Jurnal Bisnis dan Manajemen. Vol. 6 (2): 237-246.

Wahyudi, A. (2016). Determinan Pembiayaan Murabahah Pada Unit Usaha Syariah: Model Regresi Panel. Esensi: Jurnal Bisnis dan Manajemen. Vol. 6 (2): 227-236. 